\title{
Combining Grey Theory and Data Envelopment Analysis to Evaluate the Business Performance of the Vietnamese Seafood Industry
}

\author{
Dac Hung Nguyen ${ }^{1}$, Xuan Huynh Nguyen ${ }^{2}$, and Thi Kim Lien Nguyen ${ }^{3, *}$ \\ ${ }^{I}$ Department of Economics, Hung Yen University of Technology and Education, Hung Yen Province 160000, Vietnam. \\ ${ }^{2}$ Hanoi School of Business \& Management, Vietnam National University, Hanoi 100000, Vietnam. \\ ${ }^{3}$ Department of Economics-Business Administration, Thanh Dong University, Hai Duong, Hai Duong Province \\ 171960, Vietnam
}

\begin{abstract}
In recent years, the Vietnamese seafood industry is sharply growing up and being exported to many countries over the world. The purpose of this study is to evaluate the efficiency of Vietnamese Seafood companies, from past to future, by integration of the grey first-order single variables $\mathrm{GM}(1,1)$ model) using the grey theory method and the super slacked-based measure (SBM) model in the data envelopment analysis (DEA) method. First, the $\operatorname{GM}(1,1)$ model is used to estimate the future values of input and output variables during the period of 2021-2024. Second, the super-SBM model is implemented to discover the efficiency and position of Seafood companies from past to future. The main findings indicate that six Vietnamese seafood companies, including ABT, BLF, FMC, KHS, SJ1, and VHC obtain an efficiency score in both historical and future terms. Empirical results develop an overall picture of the seafood industry in Vietnam by means of a measurement of the operational process.
\end{abstract}

Keywords: Grey first-order single variable (GM,1,1) model; Super-SBM model; Data envelopment analysis; Seafood industry; efficiency scoring.

JEL Classification: C02- Mathematical Methods; F37 - International Finance Forecasting and Simulation: Models and Applications; L1 - Market Structure, Firm Strategy, and Market Performance.

\section{INTRODUCTION}

Seafood is both an important and significant food source because it has several key nutrients beneficial for human health (FAO, 2016). These benefits include high-quality protein, minerals, vitamins, and poly-unsaturated, long-chain omega 3 fatty acids (Nøstbakken et al., 2021). Themistoklis, Pirjo, and Ragnhild (2021) investigated the customer trend of using seafood such as shrimp, crab, and mussels because of their obvious health benefits. To meet the demand for seafood, the global seafood market is expanding and developing sharply, so much so that the total volume of global fish production has increased continually from 148.1 million metric tons in 2010 to 172.6 million metric tons in 2017 (Statisticsa, 2020). Many countries led in the export of fish and fishery products worldwide in 2019. These countries included China (22.7 billion USD), Norway (11.9 billion USD), Vietnam (9.5 billion USD), Chile (6.7 billion USD), and India (6.6 billion USD) (Statisticsb, 2020). Therefore, as the export of seafood products increases, it contributes significantly to the economic development of each nation. In Vietnam, the Prime Minister contributed to promoting the local seafood industry under Decision 1445/QĐ-TTg on 16

\footnotetext{
*Address correspondence to this author at Scientific Research-International Cooperation, Thanh Dong University, Hai Duong, Hai Duong Province 171960. Mobile: +84366449688; E-mail: lienntk@thanhdong.edu.vn
}

August 2013. Hence, Vietnam has manifested a large volume of fish and fishery exports with a total volume increasing from 6,728 million tons to 8,410 million tons from 20162020; additionally, it has also contributed to the economic development (GDP growth rate from 3.5\% (2016) to 5.3\% (2020)). The main export products are shrimp (44.5\%) and catfish (17.7\%). Vietnamese seafood is exported to more than 160 markets around the world and possesses six major markets: the United States, the European Union, Japan, China, Korea, and the Association of Southeast Asian Nations (ASEAN) (VASEP, 2021).

However, the export and import process of the global seafood industry has been directly influenced by the Covid-19 pandemic since regular supply chain management was postponed by the need for subsequent lockdowns to slow the pandemic (David et al., 2021). The development of the domestic Vietnamese seafood industry has also been impacted by delays directly related to the Covid-19 pandemic; thus, this study integrates two methods including, grey forecasting and data envelopment analysis to explore the past-presentfuture status of the Vietnamese seafood industry as a whole.

Grey model (GM) forecasting is utilized to estimate a future value based on the historical value, as introduced by Deng (1982). This model can deal with four continual values simultaneously that predict the short-term, the long-term, and compute a highly exact forecasting value overall. Additional- 
ly, the forecasted values check the accuracy level by using the mean absolute percentage error (MAPE); thus, all unsuitable values are removed to have a highly predicted valuation remaining. Therefore, the $\operatorname{GM}(1,1)$ model in the Grey theory has been applied in many ways. Wang, Day, and Nguyen (2018) approached the $\operatorname{GM}(1,1)$ model to forecast the future values of global third-party logistics providers. Wang, $\mathrm{Li}$, and Pei (2018) forecasted the electricity consumption of the primary economic sectors in China. Nguyen et al., (2020) used the $\operatorname{GM}(1,1)$ model to forecast the future value of new electric car sales, new battery-electric car sales, new plug-in hybrid electric car sales, and market share of sales for the electric car industry around the world. Wang et al., (2020) predicted industrial solar energy consumption in the United States. Nguyen and Luu (2021) estimated the operational business of the publishing industry in Vietnam. Moreover, other estimated models in the Holt-winters method must have a long historical time series, the future value can be computed, the grey forecasting can forecast the future value with the minimum value with four points in historical times. Therefore, the GM(1,1) model is a useful tool that many researchers have applied to predict future time based on the historical time series. In this study, we approach the $\operatorname{GM}(1,1)$ model to predict the future value of the Vietnamese fishing industry.

After gathering historical data and estimating future data, the super slack-based measure (Super-SBM) model in the DEA method is used to augment the efficiency of the Vietnamese seafood industry from past to future. DEA is a statistical method that has various models such as CCR (Charnes, Cooper, and Rhodes), SBM (slack-based measure), resampling, and so on; however, each model has a separate function with inherent characteristics. The traditional CCR model introduced by Charnes, Cooper, and Rhodes in 1978 and the SBM model developed by Tone (2001) are both applied to calculate the efficiency score of a decision-making unit (DMU). This amounts to the maximum efficiency score only attainment as one number so that it is difficult to distinguish the identity of effective DMUs. Hence, Tone (2002) set up and expanded the SBM model with super efficiency aspects called the "super-SBM model". This model can be used to discover the super-efficiency score for effective cases as determined by separate DMUs (Wang et al, 2018). Each DMU will attain a separate score, so it is easy to distinguish the efficiency level and position of each DMU according to each term. Additionally, the super-SBM model also gives input excesses and output shortfall which can recommend a feasible solution to deal with the inefficient cases. Based on these excellent characteristics, many previous researchers used this model to apply in various areas. Li and Shi (2014) indicated the energy efficiencies of industrial sectors in China from 2001 to 2010 based on the super-SBM model. Luu et al., (2017) utilized the super-SBM model to evaluate the performance of the Vietnamese banks and find out the position of each bank. Feng et al., (2018) used the super-SBM model for measuring the green innovation efficiency of China's manufacturing industry. Ding et al., (2019) used the super-SBM model for evaluating the water efficiency of Tibet and the Tibetan areas from 2006 to 2016. Tian et al., (2020) proposed the super-SBM model to measure the regional transportation sustainability efficiency in Shaanxi province, China from 2000 to 2015. Du et al., (2021) applied the super-SBM model to conduct the Marine ranching ecological efficiency of 18 marine ranches in Shandong province. As a result, this study chooses the super-SBM model to evaluate the efficiency.

An evaluation of 10 Vietnamese seafood companies past-tofuture is made by means of the integration of a $\operatorname{GM}(1,1)$ model and super-SBM model, respectively. The efficiency scores regarding their operational business process are defined by financial indicators listed in the financial reports found in Vietstock (2021). Empirical results serve to exhibit the efficient and inefficient terms of 10 Vietnamese seafood companies past-to-future, then to determine their position in every term based on their relative efficiency scores.

The paper is arranged, as follows: Section 1 introduces the purpose of this research and indicates the literature review constituting past studies of the seafood and fishery products industries, and the negative Malmquist model. Section 2 provides the mathematical equations offered by the negative Malmquist model and gives the source of the raw data. Section 3 delivers the empirical results. Finally, Section 4 summarizes the main results and gives both the limitations and the possibilities available for future research.

\section{MATERIALS AND METHODS}

\subsection{Data Collection}

Humans harvest seafood products, then the wild fish and shellfish are processed and packaged for distribution to retail and restaurants, or export to another country. This study evaluates the Seafood companies in Vietnam based on the past operating progress of selected companies. Therefore, the study chose 10 Vietnamese Seafood companies found in Vietstock (2021) (see Table 1).

Table 1. List of 10 Vietnamese Seafood Companies.

\begin{tabular}{|c|c|c|}
\hline No & Seafood Companies & Abbreviation \\
\hline 1 & Mekong Fisheries Joint Stock Company & ABT \\
\hline 2 & Cuu Long Fish Joint Stock Company & ACL \\
\hline 3 & Nam Viet Corporation & ANV \\
\hline 4 & Bac Lieu Fisheries Joint Stock Company & BLF \\
\hline 5 & Camimex Group JSC & CMX \\
\hline 6 & Sao Ta Foods Joint Stock Company & FMC \\
\hline 7 & I.D.I International Development \& & IDI \\
\hline 8 & Investment Corporation & KHS \\
\hline 9 & Kien Hung JSC & SJ1 \\
\hline 10 & Hung Hau Agricultural Corporation & VHC \\
\hline
\end{tabular}

Source: Vietstock (2021). 
Analysing the effect of operating progress requires having full and exact information of financial reports so that all of the actual and current values of input variables and output variables are present. Ten seafood companies in Vietnam, operating from 2016-2020, were collected according to their relative postings found in the financial report, Vietstock (2020). In this particular study, three input factors were chosen, including total assets (TA), selling expenses (SE), and owner's equity (OE); and two output factors, including revenue (RE), and gross profit (GP), were also selected.

\section{Input Factors}

TA: The value of marketable securities, inventories, goodwill, prepaid expenses, and so on of a seafood company.

SE: All of the money that a seafood company must pay for distributing, marketing, and selling a product and service.

OE: All of the money that a seafood company must pay-off in the event of liquidation.

\section{Output Factors}

NR: All money of a seafood company made prior to taking out the cost of business operations, cost of products, etc.

GP: The profit of a seafood company after deducting the cost of making and selling the products, cost of services, etc.

From the actual data posted to Vietstock (2021) [16], the data of input and output variables were collected and summarized in Table 2. The maximum (USD) values of TA, SE, OE, NR, and GP during the period of 2016-2020 attained $7,726,327 ; 269,403 ; 5,161,257 ; 9,271,329$; and 2,039,363, respectively. The minimum value of TA, SE, OE, NR, and GP during the period of 2016-2020 was 496,623; 12,429; 59,$729 ; 318,110$; and 37,126 , respectively. These values indicated that all input and output values were positive and were appreciated for inclusion into the $\operatorname{GM}(1,1)$ model in grey theory method and super-SBM model in the DEA method.

Table 2. Summarize the Collected Data.

\begin{tabular}{|c|c|c|c|c|c|c|}
\hline Index & Year & (I)TA & (I)CR & (I)OE & (O)OR & (O)GP \\
\hline Max & & 573,6895 & 269,403 & $2,942,616$ & $8,151,497$ & $1,171,889$ \\
\hline Min & \multirow{2}{*}{2017} & 496,623 & 19,435 & 59,729 & 383,695 & 48,114 \\
\hline Average & & $1,958,814$ & 90,024 & 855,217 & $2,465,541$ & 314,487 \\
\hline SD & & $1,834,847$ & 76,520 & 946,791 & $2,407,390$ & 337,317 \\
\hline Max & & $6,617,645$ & 210,446 & $4,015,182$ & $9,271,329$ & $2,039,363$ \\
\hline Min & \multirow{2}{*}{2018} & 535,545 & 16,745 & 138,418 & 395,938 & 90,271 \\
\hline Average & & $2,269,680$ & 89,385 & $1,095,482$ & $2,934,779$ & 531,955 \\
\hline SD & & $2,243,882$ & 66,890 & $1,255,175$ & $2,796,969$ & 590,570 \\
\hline Max & & $7,493,568$ & 251,819 & $4,877,280$ & $7,867,144$ & $1,533,082$ \\
\hline
\end{tabular}

\begin{tabular}{|c|c|c|c|c|c|c|}
\hline Min & 2019 & 524,999 & 12,429 & 157,925 & 361,150 & 54,327 \\
\hline Average & & $2,543,022$ & 100,772 & $1,317,247$ & $2,936,680$ & 462,541 \\
\hline SD & & $2,466,513$ & 80,501 & $1,491,842$ & $2,742,172$ & 464,092 \\
\hline Max & & $7,726,327$ & 185,263 & $5,161,257$ & $7,037,180$ & $1,001,066$ \\
\hline Min & \multirow{2}{*}{2020} & 526,048 & 17,812 & 159,234 & 318,110 & 37,126 \\
\hline Average & & $2,735,148$ & 88,548 & $1,392,942$ & $2,673,015$ & 308,565 \\
\hline SD & & $2,644,534$ & 63,000 & $1,550,845$ & $2,361,728$ & 278,814 \\
\hline
\end{tabular}

Source: Vietstock (2021)

\subsection{Methods}

\section{Grey First-Order Single Variable Model}

The GM(1,1) model is a forecasting tool using the grey theory system which is based on the previous time-series. This model only calculates the future data when the historical time series represents positive data and is computed in the following order:

From the primary data $X^{(0)}=\left(X^{(0)}(1), X^{(0)}(2), \ldots, X^{(0)}(n)\right)$, the consequence $X^{(1)}$ is calculated by:

$$
X^{1}(h)=\sum_{i}^{k} X^{(0)}(1) /(h=0,1, \ldots, n)
$$

Where

$$
\begin{aligned}
& h=0, X^{1}(1)=X^{0}(1) \\
& h=1, X^{1}(2)=X^{0}(1)+X^{0}(2) \\
& h=n, X^{1}(n)=X^{0}(1)+X^{0}(2)+\ldots+X^{0}(n)
\end{aligned}
$$

When having $A^{(1)}$ series, the mean equation $Z^{(1)}$ is built up:

$$
X^{(1)}(h)=\frac{1}{2}\left(X^{(1)}(h)+X^{(1)}(h-1)\right) /(h=1,2, \ldots, n)
$$

Where,

$$
\begin{aligned}
& h=1, X^{(1)}(1)=\frac{1}{2}\left(X^{(1)}(1)+X^{(1)}(0)\right) \\
& h=2, X^{(1)}(2)=\frac{1}{2}\left(X^{(1)}(1)+X^{(1)}(2)\right) \\
& h=n, X^{(1)}(2)=\frac{1}{2}\left(X^{(1)}(1)+X^{(1)}(2)+X^{(1)}(n)\right)
\end{aligned}
$$

The mathematical equation of $\mathrm{a}$ and $\mathrm{b}$ is determined by:

$$
X^{(1)}(h)+a \times Z^{(1)}(h)=b /(h=2,3, \ldots, n)
$$

Where, $a$ and $b$ are coefficients.

The linear equation of a matrix is presented by: 


$$
\begin{aligned}
& E=\left[\begin{array}{l}
X^{(0)}(2) \\
X^{(0)}(3) \\
\vdots \\
X^{(0)}(h)
\end{array}\right], D=\left[\begin{array}{cc}
-Z^{(0)}(2) & 1 \\
-Z^{(0)}(3) & 1 \\
\vdots & \\
-Z^{(0)}(h) & 1
\end{array}\right] /(h=1,2, \ldots n) \\
& \text { and } \theta=\left[\frac{a}{b}\right]\left(D^{T} D\right)^{-1} D^{T} E
\end{aligned}
$$

The whitening equation is formed:

$$
\frac{d X^{(1)}}{d t}+a \times X^{(1)}=b
$$

Set up the
$X^{(0)}=\left\{x^{(0)}(1), x^{(0)}(2), \ldots, x^{(0)}(n)\right\}(n=0,1,2, \ldots, n)$ equation is built up:

$X^{(1)}(h+1)=\left[\left(X^{(0)}(1)-\frac{b}{a}\right) e^{-a h}+\frac{b}{a}\right] /(h=1,2, . ., n)$

The forecasted values must exam the accuracy level via the mean absolute error percentage (MAPE):

$$
M A P E=\frac{100}{n} \sum_{t=1}^{n}\left|\frac{X^{(0)}(h)-X^{(0)}(h)}{X^{(0)}(h)}\right| /(h=1,2, . ., n)
$$

According to Lewis (1982), the MAPE indicator is distinguished into 4 groups: the excellent group $(10 \%<)$; the good group (10-20\%); the reasonable group (20-50\%); and, the poor group $(>50 \%)$. The unsuitable tested values needed to use another forecast model, or re-select the primary data, to be applicable.

\section{Super-SBM Model}

Data envelopment analysis (DEA) is an effective statistical method utilized in economics and operational research to estimate a production frontier to assess a DMU's efficiency. It uses the non-parametric method of benchmarking to measure the efficiency of operational research. According to the common principle of DEA, the efficiency of a DMU is to be defined by the given ratio between outputs and inputs. The Super-SBM model, created by Tone (2002), facilitates calculation and offers unlimited efficiency scores. This model was created based on an efficiency measuring method. Setting up $\mathrm{n}$ units (DMUs) with inputs are denoted by and outputs are denoted by $b$, with the business performance of each unit is defined as:

$$
\begin{aligned}
& P=(x, y) \\
& x>0, y>0
\end{aligned}
$$

The efficiency of each unit is calculated, as follows:

$$
\min p=\frac{1-\frac{1}{m} \sum_{i=1}^{m} s_{i}^{-} / x_{i 0}}{1-\frac{1}{s} \sum_{i=1}^{s} s_{i}^{-} / y_{i 0}}
$$$$
\left(s^{-}>0 ; s^{+}>0\right)
$$

The DMU will have efficiency when the score of this DMU is higher than one number. For efficient cases, the DMU does not have input excess and output shortfall.

In contrast, the DMU will not approach the efficiency when the score of this DMU is smaller than one number. For improving the inefficient scores, the input excesses must cut down, and the output shortage must extend.

\section{EMPIRICAL RESULTS}

\subsection{Estimated Values}

In the Based on the collected data from 10 seafood companies in Vietnam, these actual values are utilized to forecast the future values by the grey first-order single variable model approach. We use the input variable (TA) of ABT to illustrate the prediction process followed.

Let the primary time series $X^{(0)}$.

$$
X^{(0)}=(634,346 ; 535,545 ; 538,462 ; 543,675)
$$

Calculate time series $X^{(1)}$.

$X^{(1)}=(634,346 ; 1,169,891 ; 1,708,353 ; 2,252,028)$

Count the mean sequence $Z^{(1)}$.

$Z^{(1)}=(902,118.5 ; 1,439,122 ; 1,980,190.5)$

Formulate a and b.

$b=35,545+a \times 902,118.5$

$b=538,462+a \times 1,439,122$

$b=543,675+a \times 1,980,190.5$

Compute the linear equation.

$E=\left[\begin{array}{l}535,545 \\ 538,462 \\ 543,675\end{array}\right], D=\left[\begin{array}{cc}-902,118.5 & 1 \\ -1,439,122 & 1 \\ -1,980,190.5 & 1\end{array}\right]$,
$E T=\left[\begin{array}{cc}-902,118.5-1,439,122-1,980,190.5 \\ 1 & 1\end{array}\right]$

Determine $a$ and $b$ values.

$$
\theta=\left[\frac{a}{b}\right]\left(D^{T} D\right)^{-1} D^{T} E=\frac{-0.007544}{528360.55}
$$

Formulate the whitening equation.

$$
\frac{d 634,346}{d t}+-0.007544 \times 634,346=528360.55
$$

Estimate the forecasted value. 


$$
\begin{aligned}
& h=1, X^{(0)}(1)=634,346 \\
& h=2, X^{(0)}(2)=535,162 \\
& h=3, X^{(0)}(3)=539,215 \\
& h=4, X^{(0)}(4)=543,298 \\
& h=5, X^{(0)}(5)=547,412 \\
& h=6, X^{(0)}(6)=551,557 \\
& h=7, X^{(0)}(7)=555,734 \\
& h=8, X^{(0)}(8)=559,942
\end{aligned}
$$

Applying the above steps, the predicted values of 10 Vietnamese seafood companies from 2021 to 2024 are computed, as shown in Table A. Further, these predicted values must check the MAPEs to ensure the accuracy standard, as shown in Table 3. The MAPEs of these companies range from $1.4298 \%$ to $7.3095 \%$, with the average MAPEs for all companies being $3.7499 \%$; thus, these seafood companies have excellent predictive results. Additionally, the estimated data in Table A are positive and provide a meaningful value so that the forecasted data can be applied to measure the future efficiency via the super-SBM model in DEA method.

Table 3. MAPE Indicators.

\begin{tabular}{|c|c|c|c|}
\hline DMUs & MAPEs & DMUs & MAPEs \\
\hline ABT & $2.1181 \%$ & FMC & $1.4298 \%$ \\
\hline ACL & $3.0148 \%$ & IDI & $4.2861 \%$ \\
\hline ANV & $1.8936 \%$ & KHS & $4.3692 \%$ \\
\hline BLF & $1.8202 \%$ & SJ1 & $7.3095 \%$ \\
\hline CMX & $6.1600 \%$ & VHC & $5.0975 \%$ \\
\hline \multicolumn{4}{|c|}{ Average MAPE } \\
\hline
\end{tabular}

\subsection{Performance and Position of Seafood Companies}

Based on the rule of the DEA method, all data must be checked using Pearson's correlation coefficient to ensure the appropriate relationship between variables occurs before application into the DEA method. The relationship between two variables is always isotonic with the value being from -1 to +1 . All variables with unqualified Pearson's correlations must be removed. In this research, the Pearson correlations of 10 Vietnamese seafood companies between variables located in Tables B and C were from 0.2251 to 1 ; thus, both actual and forecasted data are deemed suitable for application to the super-SBM model in the DEA method.

In this research, we give a determination of the efficiency scores of Vietnamese seafood companies from past-to-future, as shown in Table 4.

Table 4. Performance of Seafood Companies.

\begin{tabular}{|c|c|c|c|c|c|c|c|c|}
\hline DMUs & $\mathbf{2 0 1 7}$ & $\mathbf{2 0 1 8}$ & $\mathbf{2 0 1 9}$ & $\mathbf{2 0 2 0}$ & $\mathbf{2 0 2 1}$ & $\mathbf{2 0 2 2}$ & $\mathbf{2 0 2 3}$ & $\mathbf{2 0 2 4}$ \\
\hline ABT & 1.4527 & 1.4633 & 1.3950 & 1.4774 & 1.5090 & 1.5574 & 1.5152 & 1.4931 \\
\hline
\end{tabular}

\begin{tabular}{|c|c|c|c|c|c|c|c|c|}
\hline ACL & 0.6798 & 1.1367 & 1.0169 & 0.6850 & 0.5462 & 0.4706 & 0.4759 & 0.4896 \\
\hline ANV & 0.6991 & 0.7599 & 1.1254 & 0.6328 & 0.7788 & 0.5445 & 0.4516 & 0.3657 \\
\hline BLF & 1.2562 & 2.0601 & 2.5397 & 2.4416 & 2.7073 & 2.9100 & 3.1287 & 3.3649 \\
\hline CMX & 2.1117 & 1.5435 & 1.1850 & 1.0782 & 0.9171 & 0.8777 & 1.2086 & 1.4830 \\
\hline FMC & 1.3908 & 1.6296 & 1.5822 & 2.1317 & 2.2759 & 2.8074 & 2.1618 & 1.0001 \\
\hline IDI & 0.7499 & 0.7548 & 1.3278 & 1.3085 & 1.3681 & 1.4099 & 1.4541 & 1.5008 \\
\hline KHS & 1.2571 & 1.1539 & 1.1793 & 1.3498 & 1.3169 & 1.3829 & 1.4819 & 1.6015 \\
\hline SJ1 & 1.2802 & 1.3154 & 1.5156 & 1.2381 & 1.1269 & 1.1034 & 1.1046 & 1.1311 \\
\hline VHC & 1.0000 & 1.0000 & 1.0000 & 1.0000 & 1.0000 & 1.0072 & 1.0767 & 1.1875 \\
\hline
\end{tabular}

Table 4 indicates that the efficiency scores of all seafood companies exhibit fluctuation. There are 6 companies, including ABT, BLF, FMC, KHS, SJ1, and VHC with scores above the value of " 1 " that always hold efficiency in both historical and future terms. Whereas, VHC is a unique company with a stable efficiency throughout the entire historical term and 1 future year when it owns the efficiency score as the value " 1 " in 5 consecutive years, and then its performance is predicted to increase somewhat in the future. BLF is the best seafood company that always achieves the highest efficiency score every year. Although its score in 2020 was been down because of impact of the covid-19 pandemic, it is expected to increase and achieve the highest level in the future. Four companies, including ACL, ANV, CMX and IDI, have experienced both efficient and inefficient scores. CMX, in recent years, has had a downward trend, but it still obtained a performance in historical terms with the efficiency score above the value of "1". In the future, its score will continue to recede and not attain adequate performance during the 2 future years, and then it will increase somewhat to obtain efficiency from 2023 to 2024. IDI did not arrive at efficiency in 2 historical terms, then it extended smoothly to attain efficiency in the remaining years. The efficiency scores of ACL increased in 2018, then reduced somewhat in the remaining years, only achieving adequate performance in 2018 and 2019; moreover, its score is estimated to cut off under the value of " 1 " throughout the entire future terms. ANV is considered to be the worst company because it only obtained adequate performance within the year 2019, and it did not have adequate efficiency in other years. As a result, the efficiency score for both historical and future terms is divided into 2 groups: the first group discovers the purported best seafood company (BLF); the second group determines the seemingly worst seafood company (ANV).

From the rank scores of the 10 seafood companies shown in Table 4, their position during the period of 2017-2024 is determined particularly in Figure 1. BLF made an excellent effort in which this company has tried to rank and maintain the first position from 2018 onwards. CMX only obtained the first ranking in 2017, then dropped to a lower position in the remaining years. FMC reached or will reach the second classification from 2018 to 2023, but it will sharply fall to eighth position in 2024. ABT obtained second ranking in 2017, and the third ranking within the four consecutive years from 2020 to 2023, and to fourth position in 2018, 2019, and 


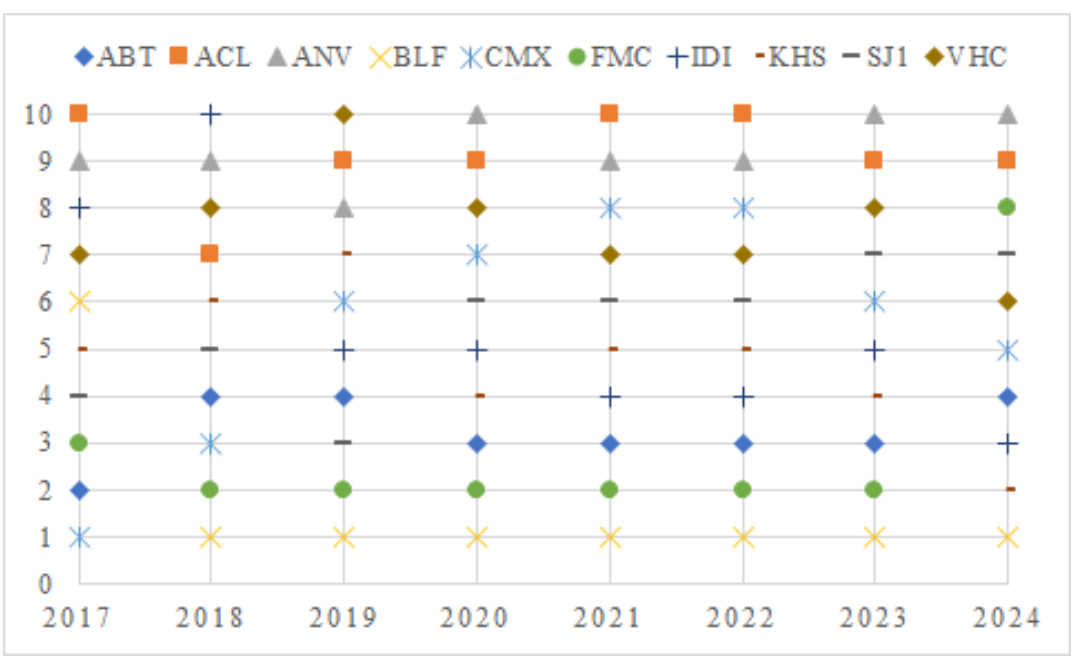

Fig. (1). Actual and predicted positions.

2024. KHS ranked from the four to sixth position in historical terms, and it is expected to approach the second ranking in 2024. In addition, IDI did not experience good business performance in the past, so its position ranked eighth and tenth ranking in 2017 and 2018, respectively; then, it extended and ranked in fourth and fifth position from 2019 until 2023. IDI is further expected to rank in third position in 2024. SJ1 had a year in which it attained third ranking in 2019, but experienced a downward trend in the following years. Although VHC had a year in which it ranked in final position, it is expected to rank in a higher position in the future. ACL and ANV always ranked in lower positions; whereas, ACL approached the seventh ranking in 2018, while in other years either the ninth or tenth position; ANV only took the ninth position and tenth position in whole terms.

A combination between the super-SBM model in the DEA method and $\operatorname{GM}(1,1)$ model in the grey theory method is proposed to measure the performance of the Vietnamese seafood companies from 2017 to 2014 and identify their position based on the efficiency score. The final empirical result reveals that BLF is the best seafood company when this company achieved the highest score in three previous terms and is estimated to hold the highest score in the future terms. By way of the consequence, BLF attains the first rank within three previous and four future terms. ANV is the worst seafood company when its efficiency score in whole terms is under one number, and both previous and future terms range the low position. Six seafood companies are excellent companies when they obtain efficiency the whole time. The remaining seafood companies have both efficiency scores and inefficiency scores; whereas, ACL and ANV are predicted to reduce sharply in the future and will not approach the performance in the future terms.

The analyzed results of 80 cases in both historical and future terms for seafood companies in Vietnam reveal 17 inefficient cases and 63 inefficient cases. For inefficient cases, they should have a feasible solution for adjusting the slacks of input and output variables to increase their efficiency score. Although many seafood companies do not impact sharply under the covid-19 pandemic, they should have a better orientation to operation in the future term because the efficien- cy score of many companies estimates to have a falling trend.

\section{CONCLUSION}

The seafood industry has a meaningful role in Vietnamese economic development. This study takes advantage of the $\operatorname{GM}(1,1)$ model and the super-SBM model to observe the efficiency score for each seafood company in Vietnam from 2017 to 2024. The efficiency scores of ten Vietnamese seafood companies are conducted by taking three inputs including, total assets, selling expenses, and owner's equity; two outputs including, revenue and gross profit.

An integration between the $\mathrm{GM}(1,1)$ model and super-SBM model is an alternative method that may be used to discover an overall picture of operational business performance in the Vietnamese seafood industry. Firstly, the $\operatorname{GM}(1,1)$ model is applied to foresee possible future values, and then the superSBM model is used to measure the efficiency and define the position. In general, most seafood companies in Vietnam represent a developmental trend; however, many companies, including ACL, ANV, BLF, CMX, IDI, and SJ1 have been deeply impacted by the COVID-19 pandemic, so much so that their efficiency scores in 2020 were deducted to form a comparison with the year of 2019.

An application of the $\operatorname{GM}(1,1)$ model is employed to forecast the accuracy-predicting values of input and output variables for 10 seafood companies in Vietnam based on a historical time-series within four consecutive years from 2017 to 2020 . The forecasting data have an accuracy standard with MAPEs from $1.4298 \%$ to $7.3095 \%$. The predictive data exhibit a forward-thinking operational business pattern during the period of 2021-2024.

Next, due to providing the best function for evaluating and ranking purposes, the super-SBM model may compute the performance and determine the position of these seafood companies. The study points out the process of business operations displayed by Vietnamese seafood companies with the evidentiary efficient and inefficient cases every year. Further, their efficiency scores also determine the position of each seafood company for every year observed. The measurement serves as a reference to support local enterprises and 
to identify their ability to create an effective operational orientation in the near future. The empirical results in this study, and others like it, recommend for customers to know about their business partners, then to select the best partner for future operations.

Moreover, the empirical results are a useful reference for the Vietnamese seafood industry to orient future business. The efficiency score for inefficient cases can improve through reducing input excess and increasing output shortfall based on the principle of the super-SBM model. Additionally, the valuable business of the seafood industry should have particular strategies such as technological and scientific development and application, high-tech application, and so on. Finally, seafood enterprises should boost to cooperate with foreign partners to extend the foreign markets.

Although the study reveals the performance of 10 seafood companies in Vietnam from past to future by integrating the $\operatorname{GM}(1,1)$ model and super-SBM model, it remains some restrictions. Firstly, inputs and outputs have not adequate to describe the operational business deeply. Further research should add more variables such as employees, capital, net profit, etc. Secondly, research only exhibits the performance of seafood companies in Vietnam without comparing with other countries. Future studies should expand the research objectives and scope in other countries. Final, research uses the $\operatorname{GM}(1,1)$ model in the grey theory method without having a comparative result of accuracy level with other models. Future studies should have more predicting models such as holt-winters and ARIMA to select the best predicting result.

\section{ACKNOWLEDGEMENT}

The authors would like to thank the Editor and reviewers for their helpful comments.

\section{CONFLICT OF INTEREST STATEMENT}

The authors declare that they have no conflict of interest.

\section{APPENDIX}

Table A. Forecasting Values.

\begin{tabular}{|c|c|c|c|c|c|c|}
\hline DMUs & Year & (I)TA & (I)SE & (I)OE & (O)NR & (O)GP \\
\hline $\mathrm{ABT}$ & \multirow{10}{*}{2021} & 547412 & 16096 & 405569 & 287396 & 22591 \\
\hline $\mathrm{ACL}$ & & 1835195 & 37789 & 784733 & 776762 & 113894 \\
\hline ANV & & 5732253 & 203846 & 2694382 & 3413420 & 523463 \\
\hline BLF & & 513764 & 102008 & 170206 & 579357 & 153033 \\
\hline CMX & & 2008294 & 47673 & 1047322 & 1578561 & 193111 \\
\hline FMC & & 1807587 & 174753 & 1354288 & 4645768 & 452185 \\
\hline IDI & & 8437657 & 140723 & 3213517 & 6837222 & 320605 \\
\hline KHS & & 743616 & 26979 & 201659 & 1197079 & 98162 \\
\hline SJ1 & & 967579 & 21809 & 301811 & 1109658 & 105017 \\
\hline VHC & & 7648339 & 177752 & 5916515 & 6041719 & 746145 \\
\hline $\mathrm{ABT}$ & 2022 & 551557 & 15209 & 401185 & 257960 & 14340 \\
\hline
\end{tabular}

\begin{tabular}{|c|c|c|c|c|c|c|}
\hline ACL & & 2043048 & 29535 & 870889 & 596269 & 72869 \\
\hline ANV & & 6794806 & 217762 & 2995710 & 3151857 & 427070 \\
\hline BLF & & 505040 & 115067 & 179439 & 598531 & 163879 \\
\hline CMX & & 2548573 & 53574 & 1945361 & 1868262 & 191903 \\
\hline FMC & & 1938059 & 210821 & 1674303 & 5028206 & 471404 \\
\hline IDI & & 9094903 & 128063 & 3411961 & 6849226 & 219905 \\
\hline KHS & & 775006 & 25628 & 200189 & 1221085 & 95800 \\
\hline $\mathrm{SJ} 2$ & & 974559 & 25077 & 310770 & 1129295 & 109395 \\
\hline VHC & & 8179029 & 163305 & 6668855 & 5252135 & 533032 \\
\hline $\mathrm{ABT}$ & \multirow{10}{*}{2023} & 555734 & 14371 & 396848 & 231539 & 9102 \\
\hline ACL & & 2274441 & 23084 & 966505 & 457717 & 46622 \\
\hline ANV & & 8054318 & 232629 & 3330738 & 2910337 & 348426 \\
\hline BLF & & 496464 & 129798 & 189174 & 618339 & 175494 \\
\hline CMX & & 3234201 & 60206 & 3613435 & 2211130 & 190702 \\
\hline FMC & & 2077950 & 254334 & 2069936 & 5442126 & 491439 \\
\hline IDI & & 9803344 & 116542 & 3622659 & 6861252 & 150834 \\
\hline KHS & & 807720 & 24344 & 198729 & 1245572 & 93494 \\
\hline $\mathrm{SJ} 2$ & & 981589 & 28834 & 319996 & 1149280 & 113955 \\
\hline VHC & & 8746540 & 150032 & 7516860 & 4565741 & 380788 \\
\hline $\mathrm{ABT}$ & \multirow{10}{*}{2024} & 559942 & 13579 & 392559 & 207824 & 5778 \\
\hline ACL & & 2532041 & 18042 & 1072618 & 351359 & 29829 \\
\hline ANV & & 9547298 & 248510 & 3703233 & 2687324 & 284265 \\
\hline BLF & & 488034 & 146415 & 199437 & 638803 & 187932 \\
\hline CMX & & 4104279 & 67658 & 6711820 & 2616922 & 189510 \\
\hline FMC & & 2227938 & 306828 & 2559057 & 5890119 & 512327 \\
\hline IDI & & $1.10 \mathrm{E}+07$ & 106057 & 3846369 & 6873298 & 103458 \\
\hline KHS & & 841816 & 23125 & 197280 & 1270550 & 91244 \\
\hline $\mathrm{SJ} 2$ & & 988669 & 33154 & 329495 & 1169618 & 118705 \\
\hline VHC & & 9353430 & 137838 & 8472698 & 3969051 & 272027 \\
\hline
\end{tabular}

Table B. Pearson Correlation in the Historical Term.

\begin{tabular}{|c|c|c|c|c|c|c|}
\hline Index & Year & $(\mathrm{I}) \mathrm{TA}$ & $(\mathrm{I}) \mathrm{SE}$ & $(\mathrm{I}) \mathrm{OE}$ & $(\mathrm{O}) \mathrm{NR}$ & $(\mathrm{O}) \mathrm{GP}$ \\
\hline (I)TA & & 1.000 & 0.899 & 0.959 & 0.922 & 0.902 \\
\hline (I)SE & \multirow{3}{*}{2017} & 0.899 & 1.000 & 0.961 & 0.962 & 0.983 \\
\cline { 4 - 7 }$(\mathrm{I}) \mathrm{OE}$ & 0.959 & 0.961 & 1.000 & 0.958 & 0.969 \\
\cline { 4 - 7 }$(\mathrm{O}) \mathrm{NR}$ & & 0.922 & 0.962 & 0.958 & 1.000 & 0.982 \\
\hline (O)GP & & 0.902 & 0.983 & 0.969 & 0.982 & 1.000 \\
\hline (I)TA & & 1.000 & 0.917 & 0.958 & 0.939 & 0.900 \\
\hline (I)SE & 2018 & 0.917 & 1.000 & 0.927 & 0.935 & 0.915 \\
\hline
\end{tabular}




\begin{tabular}{|c|c|c|c|c|c|c|}
\hline (I)OE & & 0.958 & 0.927 & 1.000 & 0.970 & 0.979 \\
\hline (O)NR & & 0.939 & 0.935 & 0.970 & 1.000 & 0.964 \\
\hline (O)GP & & 0.900 & 0.915 & 0.979 & 0.964 & 1.000 \\
\hline (I)TA & & 1.000 & 0.893 & 0.922 & 0.966 & 0.839 \\
\hline (I)SE & \multirow{3}{*}{2019} & 0.893 & 1.000 & 0.931 & 0.932 & 0.944 \\
\hline (I)OE & & 0.922 & 0.931 & 1.000 & 0.936 & 0.963 \\
\hline (O)NR & & 0.966 & 0.932 & 0.936 & 1.000 & 0.873 \\
\hline (O)GP & & 0.839 & 0.944 & 0.963 & 0.873 & 1.000 \\
\hline (I)TA & & 1.000 & 0.768 & 0.931 & 0.911 & 0.837 \\
\hline (I)SE & & 0.768 & 1.000 & 0.772 & 0.827 & 0.839 \\
\hline (I)OE & & 0.931 & 0.772 & 1.000 & 0.909 & 0.958 \\
\hline (O)NR & 2020 & 0.911 & 0.827 & 0.909 & 1.000 & 0.911 \\
\hline (O)GP & & 0.837 & 0.839 & 0.958 & 0.911 & 1.000 \\
\hline
\end{tabular}

Table C. Pearson Correlation in the Future Term.

\begin{tabular}{|c|c|c|c|c|c|c|}
\hline Index & Year & (I)TA & (I)SE & (I)OE & (O)NR & (O)GP \\
\hline (I)TA & & 1.000 & 0.705 & 0.907 & 0.886 & 0.757 \\
\hline (I)SE & \multirow{3}{*}{2021} & 0.705 & 1.000 & 0.718 & 0.783 & 0.898 \\
\hline (I)OE & & 0.907 & 0.718 & 1.000 & 0.840 & 0.894 \\
\hline (O)NR & & 0.886 & 0.783 & 0.840 & 1.000 & 0.807 \\
\hline (O)GP & & 0.757 & 0.898 & 0.894 & 0.807 & 1.000 \\
\hline (I)TA & & 1.000 & 0.590 & 0.879 & 0.825 & 0.621 \\
\hline (I)SE & \multirow{3}{*}{2022} & 0.590 & 1.000 & 0.590 & 0.704 & 0.908 \\
\hline (I)OE & & 0.879 & 0.590 & 1.000 & 0.757 & 0.775 \\
\hline (O)NR & & 0.825 & 0.704 & 0.757 & 1.000 & 0.729 \\
\hline (O)GP & & 0.621 & 0.908 & 0.775 & 0.729 & 1.000 \\
\hline (I)TA & & 1.000 & 0.474 & 0.828 & 0.748 & 0.428 \\
\hline (I)SE & \multirow{3}{*}{2023} & 0.474 & 1.000 & 0.446 & 0.638 & 0.919 \\
\hline (I)OE & & 0.828 & 0.446 & 1.000 & 0.657 & 0.591 \\
\hline (O)NR & & 0.748 & 0.638 & 0.657 & 1.000 & 0.648 \\
\hline (O)GP & & 0.428 & 0.919 & 0.591 & 0.648 & 1.000 \\
\hline (I)TA & & 1.000 & 0.369 & 0.727 & 0.660 & 0.225 \\
\hline (I)SE & & 0.369 & 1.000 & 0.289 & 0.593 & 0.920 \\
\hline (I)OE & & 0.727 & 0.289 & 1.000 & 0.537 & 0.388 \\
\hline (O)NR & 2024 & 0.660 & 0.593 & 0.537 & 1.000 & 0.587 \\
\hline (O)GP & & 0.225 & 0.920 & 0.388 & 0.587 & 1.000 \\
\hline
\end{tabular}

\section{REFERENCES}

Charnes, A., Cooper, W. W., and Rhodes, E. 1978. Measuring the Charnes, A., Cooper, W. W., and Rhodes, E. 1978. Measuring the efficiency

of decision-making units. European Journal of Operational Research, 2(6), 429-441.

https://doi.org/10.1016/0377-2217(78)90138-8.

David, C. L., et al. 2021 Emerging COVID-19 impacts, responses, and lessons for building resilience in the seafood system, Global Food Security, 28, 1-11. https://doi.org/10.1016/j.gfs.2021.100494.

Deng, J. L. 1982. Control problem of Grey systems. Systems \& Control Letters, 1, 288-294, doi:10.1016/S0167-6911(82)80025-X.

Ding, X. H., Zhang, Z. X., Wu, F. P., Xu, X. Y. 2019 Study on the Evolution of Water Resource Utilization Efficiency in Tibet Autonomous Region and Four Provinces in Tibetan Areas under Double Control Action. Sustainability, 11 (12), 1-11 https://doi.org/10.3390/su11123396

Du, Y. W., Jiang, J., Li, C. H. 2021. Ecological efficiency evaluation of marine ranching based on the Super-SBM model: A case study of Shandong. Ecological Indicators, 131, 1-12. https://doi.org/10.1016/j.ecolind.2021.108174

FAO, 2016. The State of World Fisheries and Aquaculture 2016. Contributing to Food Security and Nutrition for All. FAO, Rome

Feng, Z., Zeng, B., Ming, Q. 2018. Environmental Regulation, Two-Way Foreign Direct Investment, and Green Innovation Efficiency in China's Manufacturing Industry. International Journal of Environmental Research and Public Health, 15(10), 1-22. https://doi.org/10.3390/ijerph15102292.

Lewis, A. 1982. The social psychology of taxation. British of social psychology of taxation. 21, 151-158. https://doi.org/10.1111/j.20448309.1982.tb00523.x.

Li, H., Shi, J. F. 2014. Energy efficiency analysis on Chinese industrial sectors: an improved Super-SBM model with undesirable outputs, Journal of Cleaner Production, 65, 97-107. https://doi.org/10.1016/j.jclepro.2013.09.035.

Luu, Q. C., Lin, G. H., Nguyen, N. B. T. 2017. Using Super SBM Model for ranking: A case study of banks in Vietnam. International Conference on System Science and Engineering (ICSSE), 625-628, doi: 10.1109/ICSSE.2017.8030950.

Nguyen, T. K. L., Le, H. N., Ngo, V. H., Hoang, B. A. 2020. CRITIC Method and Grey Theory in the Study of Global Electric Cars. World Electric Vehicle Journal, 11 (4), 1-15. https://doi.org/10.3390/wevj11040079

Nguyen, X. H., Luu, Q. C. 2021. Performance Measurement of Vietnamese Publishing Firms by the Integration of the $\operatorname{GM}(1,1)$ Model and the Malmquist Model. Business Systems Research, 12(1), 17-33. DOI: 10.2478/bsrj-2021-0002.

Nøstbakken, O.J, Rasinger, J.D, Hannisdal R, Sanden M, Frøyland L, Duinker A, Frantzen S, Dahl LM, Lundebye AK, Madsen L. 2021. Levels of omega 3 fatty acids, vitamin D, dioxins and dioxin-like PCBs in oily fish; a new perspective on the reporting of nutrient and contaminant data for risk-benefit assessments of oily seafood. Environment International, 147, 1-11. DOI: $10.1016 /$ j.envint. 2020.106322 .

Statistics. 2021. Global fish production from 2002 to 2019. Available online: https://www.statista.com/statistics/264577/total-world-fishproduction-since-2002/. Accessed on 11 June 2021.

Statistics. 2021. Leading exporting countries of fish and fishery products worldwide in 2020 (in billion U.S. dollars). Available online: https://www.statista.com/statistics/268269/top-10-exportingcountries-of-fish-and-fishery-products/. Accessed on 11 June 2021.

The Prime Minister. 2013. Approving the General Planning of Seafood Industry Up to 2020 and Vision to 2030. No. 1445/QĐ-TTg; The Prime Minister: Hanoi, Vietnam.

Themistoklis, A., Pirjo, H., Ragnhild, D. W. 2021. Influence of the involvement in food waste reduction on attitudes towards sustainable products containing seafood by-products, Journal of Cleaner Production, 285, 1-13. https://doi.org/10.1016/j.jclepro.2020.125487.

Tian, N., Tang, S. S., Che, A., Wu, P. 2020. Measuring regional transport sustainability using super-efficiency SBM-DEA with weighting preference, Journal of Cleaner Production, 242, 1-11. https://doi.org/10.1016/j.jclepro.2019.118474.

Tone, K. 2001. A slacks-based measure of efficiency in data envelopment analysis. European Journal of Operational Research, 130, 498-509. DOI: https://doi.org/10.1016/s0377-2217(99)00407-5.

Tone, K. 2002. A slacks-based measure of super-efficiency in data envelopment analysis. European Journal of Operational Research, 143, 32-41. DOI: https://doi.org/10.1016/s0377-2217(01)00324-1.

Vietnam Association of Seafood Exporters and Producers. Overviewing of Vietnam Association of Seafood Exporters and Producers. 
Available online: http://vasep.com.vn/gioi-thieu/tong-quannganh\%20(accssed\%20on\%2011/6/2021). Accessed on: 01 June 2021.

Vietstock. 2021. Available online: https://vietstock.vn/. Accessed on 15 March 2021.

Wang, C. N., Day, J. D., Nguyen, T. K. L. 2018. Applying EBM Model and Grey Forecasting to Assess Efficiency of Third-Party Logistics Providers. Journal of Advanced Transport, Article ID 1212873. https://doi.org/10.1155/2018/1212873.

Wang, C. N., Day, J. D., Nguyen, T. K. L., Luu, Q. C. 2018. Integrating the Additive Seasonal Model and Super-SBM Model to Compute the
Efficiency of Port Logistics Companies in Vietnam. Sustainability, 10,1-17.

https://doi.org/10.3390/su10082782.

Wang, Z. X., Wang, Z. W., Li, Q. 2020. Forecasting the industrial solar energy consumption using a novel seasonal $\operatorname{GM}(1,1)$ model with dynamic seasonal adjustment factors, Energy, 200, 1-11. https://doi.org/10.1016/j.energy.2020.117460.

Wang, Z. X., Li, Q., Pei, L. L. 2018. A seasonal GM(1,1) model for forecasting the electricity consumption of the primary economic sectors, Energy, 154, 522-534, https://doi.org/10.1016/j.energy.2018.04.155

Received: May 02, 2021

Copyright $\odot$ 2021- All Rights Reserved

This is an open-access article. 